\title{
Can deliberate efforts to realise aspirations increase capabilities? A South African case study
}

\author{
Ina Conradie
}

\begin{abstract}
This paper takes up Appadurai's suggestion that aspirations could be used as a key to unlock development for people who are economically marginalised, and that their capabilities could be increased by this approach. The notion of "aspirations" is theoretically and conceptually framed, and then Amartya Sen's use of the term capabilities as the space within which development should be assessed is explored. I subsequently describe a five-year programme in which economically marginalised women in Khayelitsha near Cape Town were assisted in voicing and attempting to realise their aspirations, while being assisted with access to some resources. Capability outcomes and constraints are described and analysed, and the question of adaptive preferences is addressed. I conclude that deliberate efforts to realise aspirations, accompanied by some facilitation, can increase capabilities, but that there are also structural constraints to capability expansion for these women that frustrate their aspiration of class mobility.
\end{abstract}

\section{Introduction}

When novelist and philosopher Pascal Mercier wrote about the quest of Raimund Gregorius to discover what other lives he could have lived apart from the one he was actually living, the author touched on a universal theme. ${ }^{1}$ Among all the opportunities available to us, few are actually translated into action, for different and complex reasonsour own aspirations and choices at given times in our lives, our socio-economic circumstances and capability, the collective values of the society we live in, our specific personalities, history and agency, personal relationships and many more. The question then arises how much freedom of choice the poor or economically marginalised have-for example, if one is not sure where tomorrow's meal will come from, does this influence one's choices, especially the choices that concern the direction of one's life? Can one aspire to live another kind of life, and more pertinently, can one work towards such a life?

These questions are addressed by anthropologist Arjun Appadurai's provocative suggestion that the poor have to be taught the capacity to aspire as this capacity is often absent in the lives of the poor, and that this lack acts as a severe constraint to overcoming poverty. Appadurai also recommends that this cultural assumption 
should be explored within the capability approach-that the deliberate articulation of aspirations by the poor could open a door to increased capabilities (Appadurai, 2004). By capabilities is meant the different structural opportunity sets open to an individual, within which she would be able to exercise choice and agency, thereby increasing her functionings, or beings and doings. These choices would reflect that which she values or has reason to value.

In this paper, I will describe a five-year programme of action research which operationalised this idea in Cape Town, South Africa. This programme gave a group of women from a very poor neighbourhood the opportunity to express and reflect on their aspirations and the chance to work on these aspirations with a limited amount of support.

A literature survey by Ingrid Robeyns of studies which used the capability approach identifi nine kinds of ways in which the approach has been practically applied (Robeyns, 2006). This study is an example of the second kind of application she identifi d, namely an assessment of a small-scale development project. It takes the form of a normative assessment of functionings and capabilities, done by means of action research, where assessment and intervention are inextricably linked. It also deals with a prospective application of the approach, asking whether actions undertaken in order to realise aspirations can increase a person's capabilities (Alkire, 2008, p. 30). The study of aspirations deals particularly with the will, motivation and determination of the individual, albeit within a context where she is constrained by what is available. If aspirations could be used deliberately, they could be seen as a potential tool for poverty reduction and for the activation of agency.

I deal below with the theoretical and conceptual discussion of aspirations and of poverty as capability deprivation. This is followed by a historical sketch of the township Khayelitsha, near Cape Town in South Africa, and a review of the socio-economic conditions the participating women face, as well as of their opportunities and capability constraints. The description of the action research programme in Khayelitsha is followed by an analysis of the fieldwork, asking whether the work on aspirations has increased the women's capabilities. I conclude by asking what the research has shown regarding the role of aspirations in poverty reduction and by examining possible implications of the research.

\section{Conceptualising Aspirations}

Whereas a focus on needs, and particularly basic needs, implies that needs satisfaction is essential for sustaining life and a basic standard of living, the term aspirations evokes the idea of a person's life dreams; how one could have a "good life" with the resources of health, material benefits, creativity and agency one has available. It speaks to ideals, ambitions, longings-achievements which would make life worthwhile and which would transcend the daily struggle for survival. Appadurai furthermore makes the point that material needs and aspirations are also related to norms and values-that the category of

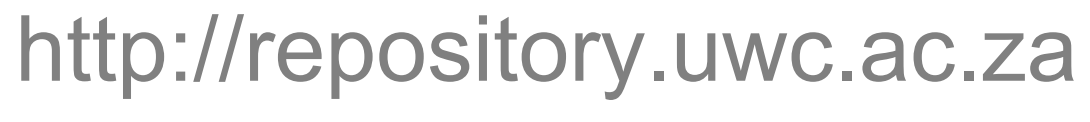


"needs" represents the "immediate, visible inventory" of other "intermediate and higher order normative contexts within which these wants are gestated and brought into view" (2004, p. 68). Aspirations can therefore be said to deal with both material needs and nonmaterial hopes and dreams, as well as with the values and norms which shape them. The values can be personal or social, and realising goals which are linked to the person's own value system can be highly motivating. These categories, moreover, are not necessarily separable but often act in unison.

Appadurai's anthropological work is novel in the sense that it suggests an intervention-the enhancement of the capacity to aspire-in programmes which deal with the poor. The reason for this is that the ability to aspire is one which improves with practice and repetition and diminishes with neglect (2004, p. 69). There is therefore a natural affiliation between these ideas and the methodology suggested by Sen of reflection and consultation with those whose capabilities are being assessed and addressed in order to engage their understanding of their own context, their perceptions about which dimensions would be most crucial to assess and their agency in making choices and taking action.

Appadurai emphasises that culture is to be seen as the terrain where all social and economic life is played out in a complex pattern of interrelating factors and actions which deal with the whole of life. And yet, it has been seen as synonymous with tradition and "pastness" (Appadurai, 2004, p. 60). As the poor in the developing world therefore make the complex transition between traditional ways of life and of obtaining a livelihood, to ways of living associated with a global economy and lifestyle, they have to negotiate different ideas within the cultural sphere-"culture is a dialogue between aspirations and sedimented traditions" (Appadurai, 2004, p. 84). Seen in this way, culture becomes a study of the future, and by helping the poor to access their aspirations, they are assisted in entering the future.

Appadurai furthermore sees the problem as one of changing "the terms of recognition". This rich term, introduced by Charles Taylor (1992), refers to norms and frameworks of recognition which early sociologists such as Durkheim and Mead identified. "There is no self outside a social frame, setting and mirror" (Appadurai, 2004, p. 67). The terms of recognition relate firstly to social and political frames of recognition and therefore how others see us. They are, however, also closely related to how we see ourselves and to how our personal and cultural identities are shaped by how others see us and expect to see us. It is well known that oppressed people often comply and identify with cultural systems which deny them rights and choices (Fanon, 1986). In fact, Appadurai (2004, p. 65) says that the poor relate to the dominant norms of society in a deeply ambivalent way, not only with irony and cynicism, but also with a "fairly deep moral attachment to norms and beliefs that directly support their own degradation". Changing the terms of recognition would therefore imply that the investigator would ask whether the poor are stigmatised and therefore constrained by their class position and whether they indeed subscribe to these terms themselves.

Aspirations are always formed "in the thick of social life" (Appadurai, 2004, p. 67), in collective contexts and in the space where cultural values and norms are received and

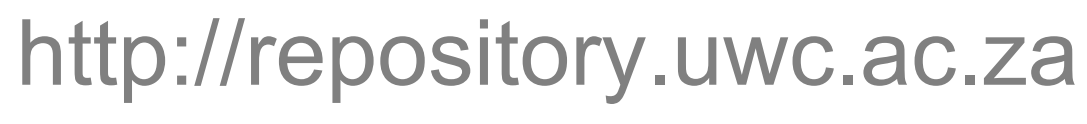


reshaped. Social and cultural identities are constructed by ourselves and by others (Berger \& Luckman, 1966; Giddens, 1991; Searle, 1995; Hacking, 1999; Castells, 2004). The ways in which the women in the study participate in the construction of their own class and cultural identity will be discussed below.

Appadurai and others have given us a better understanding of the notion of "aspirations". The research underlying this paper aimed to encourage women to "work on aspirations", meaning that women's aspirations were actively discussed, after which some were given priority and some practical assistance was given to support the chosen aspirations. The "active discussions" included a life skills course (see Table 1) where the women reflected on their life experiences and on societal constraints. These discussions prepared them for the selection of one key aspiration which they would subsequently attempt to realise. The work on their aspirations also included training courses in sewing, nursing or catering to increase their skills. Limited support was then given for the realisation of their key aspiration, in the provision of stoves and sewing machines, a collective work space and regular group discussions which gave the opportunity to raise problems and support each other. ${ }^{2}$ 


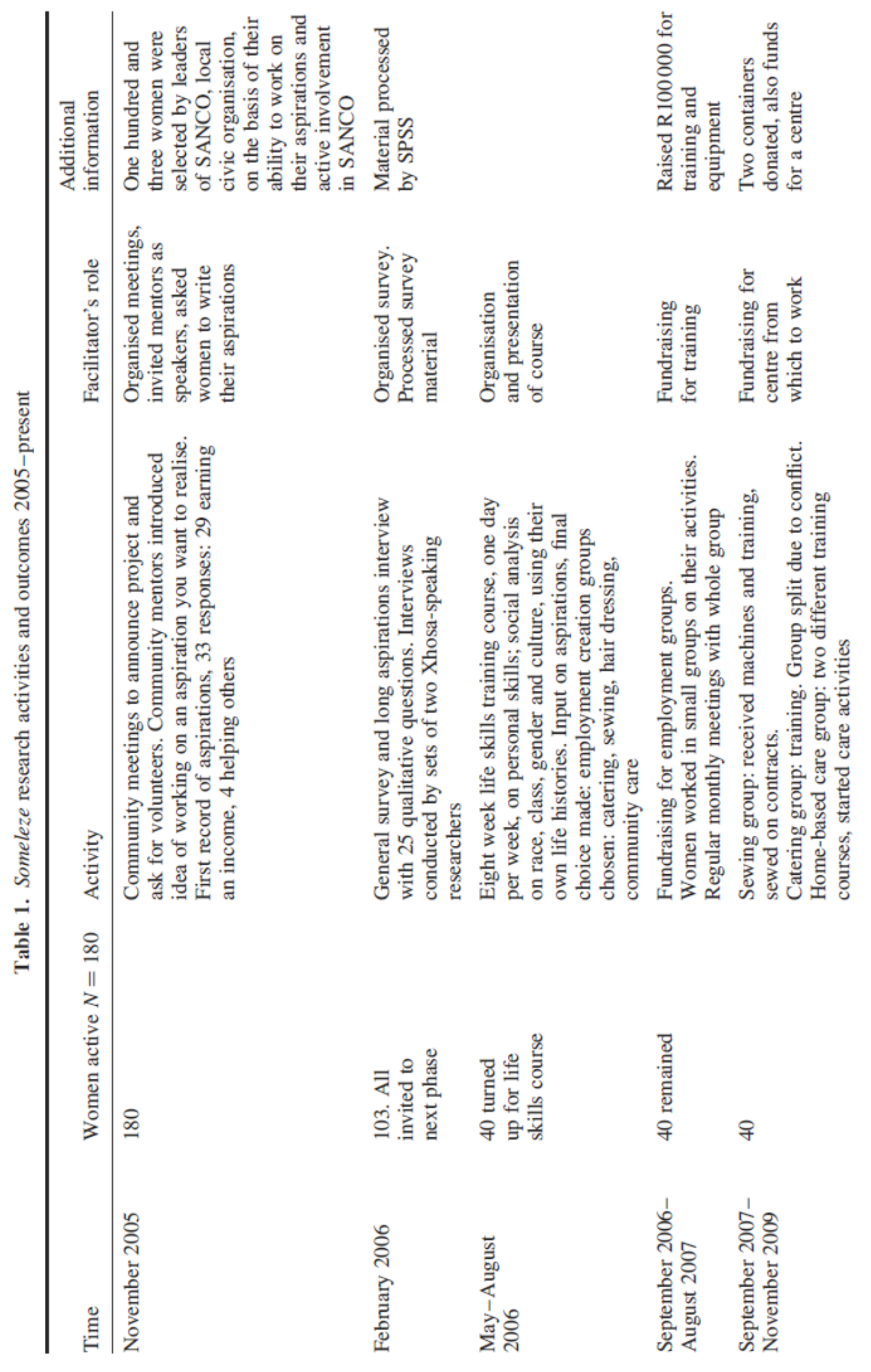

http://repository.uwc.ac.za 


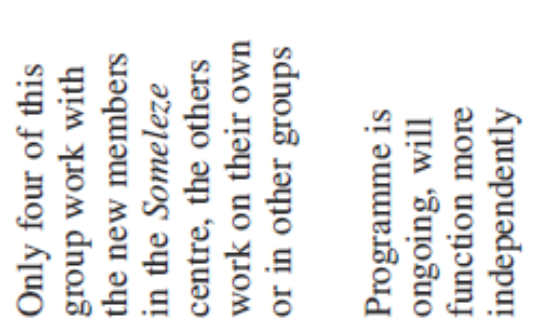

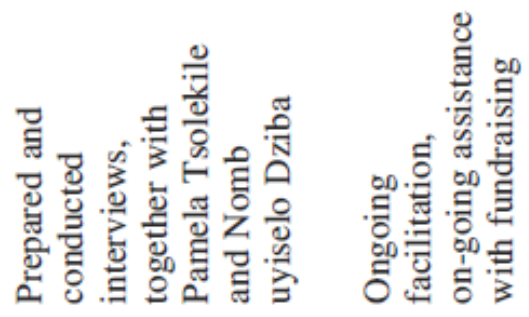

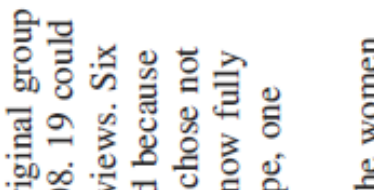

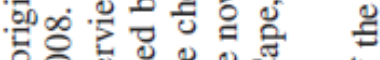

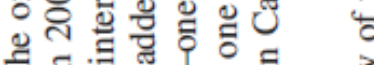

. .

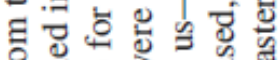

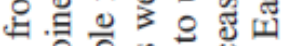

느워

औ灵 है

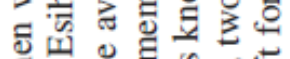

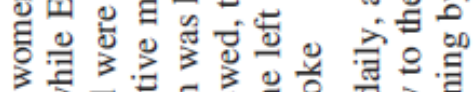

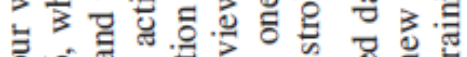

के

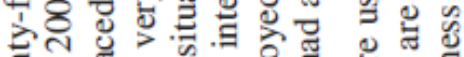

ฮี

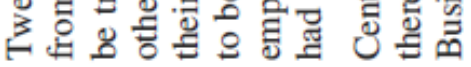

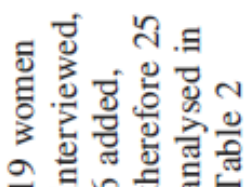

ด.

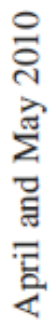

网

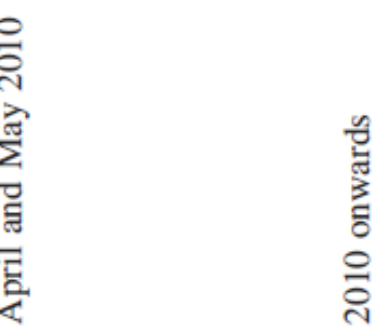


We now need to turn to the second main concept at work in the action research programme which is analysed in this paper-the idea of understanding poverty as capability deprivation.

\section{Poverty as Capability Deprivation}

Amartya Sen (1999) suggests that poverty may primarily be seen as capability deprivation. This would imply that there are a number of ways in which a person's life situation may increase her ability to escape a life of poverty. The main way would be through structural opportunities and the extent to which she is able to exercise choice about using the opportunities and the resources at her disposal, in such a way that these choices express the things she values or has reason to value (Alkire \& Deneulin, 2009). Her own values are therefore crucially important in her decisions about how to make her way out of poverty, but so are the reasonable and universal values which a just society would hold. A society which limits social and legal institutional support to the poor, or the means to achieve their reasonable aspirations within its policy frameworks, is not providing either a human development environment or the capability to overcome poverty. Over and above these institutional problems, there may be personal, social or environmental conversion factors which might curtail the ways in which the poor can convert resources into functionings and which would thus limit their capability expansion (Robeyns, 2005).

A person's achieved beings and doings are her functionings while capabilities are potential functionings which could be realised at any time. Both functionings and capabilities can be measured or assessed by looking at dimensions identified by researchers and others participating in public discussion with the poor and their formal and informal leaders 3 (Comim, 2008). Such dimensions could include intangible dimensions such as emotions (Goldin, 2011). In the case of capabilities potential to achieve is assessed; in the case of functionings, actual achievement is the focus. When a person is able to use her aspirations in such a way that she is able to achieve the functionings she wishes to have, she has used her agency to realise the capabilities available to her in order to enable her to live the life she most deeply wants to live.

There might, however, be serious constraints in the realisation of capabilities. These may be historical, structural, cultural, or also personal, and thus linked to agency. It is essential that these constraints or obstacles be assessed as comprehensively as possible when capabilities are assessed, as they are an inherent part of the space in which capabilities can be realised (Robeyns, 2010) and might in fact be the reason why aspirations cannot be realised sufficiently. An important factor inhibiting people's choices is that they might adapt their choices to less ambitious options, therefore adjusting their aspirations to a lower level-the so-called adaptive preference problem (Sen, 1985, 1992, 2002; Nussbaum, 2000; Clark \& Qizilbash, 2008, Qizilbash, 2009). This raises the question again of the possibility of assessing freedom or capability in a setting of extreme poverty and deprivation. Is genuine choice possible when the range of options is drastically 
reduced? Because of this question the researcher has to constantly be aware that adaptation might be taking place, and ensure that it becomes part of the analysis. David Clark nevertheless points out that research shows that adaptive behaviour is not ubiquitous, and that it can moreover also be an upward adaptation, which means that preferences and choices could be adjusted to be higher than what they would have been, for example, when respondents to a questionnaire increase their aspirations on being presented with possibilities they might not have contemplated before (Clark, 2009).

Tania Burchardt moreover recently argued that the conditions of autonomy or lack of autonomy under which aspirations are formed should be an inherent part of the assessment of aspirations. "Identical capability sets do not afford the same real chance, in practice, of achieving valuable functionings, and the reason for this difference is aspirations formed in previous unequal and unjust conditions" (Burchardt, 2009, p. 9). This would obviously apply in the case of thewomen inKhayelitsha being discussed here. The evidence for adaptation and specifically upward adaptation in the Khayelitsha group will be discussed below.

The question of whether capabilities should be assessed individually or collectively is one which has been extensively explored (Alkire, 2008; Robeyns, 2008). A number of authors have argued for the space to conduct collective applications of the approach as well (Stewart, 2005; Ibrahim, 2006; Smith \& Seward, 2009). In this study, all assessments were done individually, but the intervention was both individual and collective. In choosing their preferred form of action, the participating women sometimes chose to act in groups and sometimes acted individually, depending on the circumstances.

Aspirations could possibly be seen as one of the keys to increasing the awareness of the poor of the range of capabilities they could potentially choose from. To the extent that capability constraints can be removed, in the process of voicing, expressing and working on aspirations (as will be explored in the empirical material below), increased functionings could reveal the impact of aspirations where previously there had been limited deliberate exercise of personal choice.

\section{Khayelitsha: Description of the Research Context}

\subsection{Historical Background}

Rural-urban migration in South Africa was partly induced by colonial governments which needed African labour in the urban areas. Hut and head taxes were used to compel young men to work in the mines and this gradually transformed the agrarian population by means of a process of monetisation (Bundy, 1988; Wolpe, 1988; Du Toit \& Neves, 2008). After a few decades of increasing urban migration the rural subsistence economy virtually collapsed (Simkins, 1983). This coincided with the stated intention of the apartheid regime to allow no Africans into the Western Cape, and the drawing of the so-called "Eiselen line" in 1955, which would operate as a border of social and economic exclusion for Africans (West, 1982). People nevertheless came to the urban areas for work because of better work opportunities and because of the impoverishment of the rural areas, and this led to a dramatic and prolonged confrontation between government forces and the urbanising Xhosa-speaking 
people in Cape Town (Giliomee \& Schlemmer, 1985; Cole, 1987). When it became clear that the tide of migrants would not be stemmed, Khayelitsha was planned and built $25 \mathrm{~km}$ from central Cape Town to house the thousands of people streaming into the Western Cape by 1984 (Conradie, 1991). The Influx Control legislation was finally repealed in 1986 and Khayelitsha, meaning "New Home", now houses between one and one and a half million people (Sogayise, 2009). 4

Currently, 19 years after the democratisation of South Africa, the predominantly rural Eastern Cape and the largely urban Western Cape are socially and economically integrated as far as Xhosa-speaking people are concerned. Most families have members and in fact households in both areas, and there are extensive networks of informal support which operate in both directions (Du Toit \& Neves, 2008, 2009). It is therefore important to observe that poverty in South Africa is a continuation of the trends associated with not only apartheid but also the colonial project, "modernisation", and the resulting socioeconomic processes of migration and urbanisation. As such it has a racial identity, despite the many efforts that have been made since 1994 to reverse social and economic exclusion based on race (see Terreblanche, 2002, pp. 23-139).

The democratisation which followed apartheid and centuries of colonial history in South Africa brought with it a good constitution and representative democracy. One of the questions which was asked during the design of this research was whether the oppressive history of the residents of Khayelitsha had affected their capacity to aspire to a different future, in the way which Appadurai suggests. The various threads which will allow us to respond to this question will be pursued.

\subsection{Socio-economic Conditions of Women in Khayelitsha}

Since 2006, I have been working with a group of women volunteers in Site C, a neighbourhood of Khayelitsha, on the realisation of their aspirations. At that time the women all lived in shanties or "shacks", but many now live in brick houses, provided by the government housing subsidy. Unemployment was very high, and only $21.6 \%$ of the women had done some work for gain during the 10-day period before the survey, although there was at least one job which generated an income in $60 \%$ of the households. 5 Many of them relied on child support grants of R190 per month per child,6 up to the age of thirteen, to survive7and $77 \%$ of the group said that their household had not had enough to eat during one week of the previous month (Conradie, 2009). It is however useful to remember that the inhabitants of Khayelitsha although poor, sometimes even extremely poor, have not experienced long periods of inter-generational poverty. One or two generations before them most people had productive land and were economically self-sufficient. They are therefore more likely to aspire to something different and to respond to the idea of a "good life", than if that had not been the case.

The women's situation should also be seen against the background of poverty in South Africa. Although overall poverty has decreased marginally since the end of apartheid, it remains acute for the African and Coloured groups. It has also increased in urban areas. 
Non-monetary indicators of well-being such as brick housing, piped water and electricity have improved continuously, which had an impact on poverty, as will also be seen in the findings of the study. Inequality consistently increased in South Africa over the period since 1994, both between and within racial groups (Leibbrandt, 2010).

\subsection{Development Constraints in Khayelitsha}

In a fast-changing society such as South Africa, a person's class position would normally be determined by occupation and income, which are closely related to education. All the women except one who had been to university and who has potential access to a middle class income were poor when the programme started, with very few family members employed. A small number could therefore possibly be categorised as working class, but the majority are economically considerably worse off than the working class, and a class analysis is therefore difficult, except possibly to suggest that they form a marginalised underclass (Seekings \& Nattrass, 2005, pp. 271-299).

An obstacle which almost half of the women emphasised is their lack of proper education, which they think is what constrains them most. This might well be so-in the whole group of 103 women $58.9 \%$ had attempted grade 12 , the final year at school with a public examination, and $28.5 \%$ had succeeded (Conradie, 2009). The quality of the education they received, with or without grade 12, has however been poor and this has proved to be debilitating for realising their aspirations. The women are constrained in the achievement of their aspirations and capabilities by their lack of education, and particularly their inability to use English as medium-a key to economic involvement in the broader society. They are perceived, by themselves and others, as lacking in that which would have given them access to the world of work in a modern city such as Cape Town.

Their gender position has ambivalent effects. It became clear that most of the women in this group refuse to adhere to cultural beliefs which prescribe gender roles in their behaviour towards their husbands, and men in general. It can therefore be seen that the women in this group are reshaping their cultural context to accommodate a value on which they will not negotiate-the freedom to act in their own and their children's interest. This is an example of how the women actively participate in constructing the terms of recognition which relate to their lives. Most of them felt that being a woman was not a constraint in itself. A general and central theme was the issue of independence and the fact that they strove for financial and general autonomy. Interestingly, only $26 \%$ of the women in the initial group of 103 participants were married, while $62 \%$ had never married, though almost all the women had children. This is in line with the findings of the Cape Area Panel Study (CAPS) according to which $47.5 \%$ of all women in Khayelitsha had never married, while $24 \%$ were married (Lam et al., 2008; Conradie, 2009). The need for financial and social independence voiced here might be one reason for this phenomenon, but it needs further study. While gender relations within their own cultural sphere can be changed by their own actions, gender relations in the broader society and in the work place are a different matter. Although women have benefited from Affirmative Action policies in South Africa, gender attitudes among men and sometimes in society as a whole are often still conservative and restrictive. 
The role which cultural perceptions can play in the realisation of aspirations was also examined. In the predominantly Xhosa-speaking community of Khayelitsha it is quite common to hear people refer to "how things are done in our culture", referring to culture as both enabling and constraining. The question which was asked on this was "Can you achieve your ideals within your own culture, and how?" Fifteen of the respondents believe very strongly that without their culture and customs, they are not able to live or succeed at anything. Some of the responses were:

You have to follow them and grow in them and if you don't you will go nowhere. (Nomaliso, interviewed on 13 April 2010)

That's our life. If you don't have tradition or culture you are not a person. (Nozuko, interviewed on 20 April 2010)

Three of the women did not express the same unconditional views on culture. They took an in-between position, saying that culture and modernity, the church and one's own efforts are all important.

Rather than to copy our ancestors' style, we do what is right now. I'm not saying that we leave culture behind. (Vida, interviewed on 21 May 2010)

One of the questions which we asked in the 2010 interviews was "Has anyone tried to prevent you from achieving your aspirations?" The reason for this question is that the women pointed out in a focus group in 2009 that they are often prevented from being successful and that they are "pulled down" by each other. Two people indirectly connected to the group also told me in the last year about being prevented from achieving academic success by others who are jealous of them, and who then allegedly procured traditional medicines from a traditional healer to harm them. For this they then had to get protection of their own (see also Ashforth, 1996; Schech \& Haggis, 2000, p. 149; Steinberg, 2008). The women in the group however did not refer to this phenomenon directly-one only pointed to the beads on her wrists and said: "I have my own protection". This cultural phenomenon can clearly have an impact on whether one feels free to realise her aspirations. At the same time people do not readily talk about it, and it is therefore not clear what role it plays.

In order to be able to analyse the constraints experienced by the women in the study, the impact on their lives of the history discussed above has to be taken into account. African people born in the Western Cape often refer to themselves as "borners", thereby socially excluding those born in the rural area. This is a dynamic which is still present, 27 years after the abolition of Influx Control, and the women in the study face low social status by virtue of being from the Eastern Cape, by being women and by being both poorly educated and poor. These perceptions or "terms of recognition" form an interpretative frame which is very difficult to overcome, and these women are up against this in striving to achieve their 
aspirations. In comparison, cultural constraints seem easier to overcome, as these exist in their own sphere, and not on the boundary between their geographically isolated society and the broader one. Moreover, many of their cultural norms are seen to have considerable value, and only those that relate to gender evoke a negative response amongst almost all of these women.

\subsection{Action Research on Aspirations in Khayelitsha}

In this section, the phases of the action research process will be described. This will include the inputs which were made by the researcher and observations on those made by government during the period under discussion. That is followed by the presentation of the results of the fieldwork.

\subsection{The Action Research Process}

Towards the end of 2005 I invited women from Site C in Khayelitsha to participate in a SANPAD sponsored programme of working on their aspirations. ${ }^{8}$ This was negotiated through SANCO, the South African National Civic Organisation, which has a system of street committees in many areas to which all households belong. Most of the women who volunteered to participate heard about the programme through their street committee. During the first phase in 2005 all interested women could fill in a form and return it to the Site C street committees. Out of 180 forms, the SANCO leaders selected 103 individuals to participate, on the basis of their active involvement in SANCO and the street committees, as well as what the SANCO committee saw as their potential to work on their aspirations. The phases of the programme are summarised in Table 1 (Conradie, 2009). 9

Early in 2006 a household survey was conducted with the 103 selected women on household composition, household assets, household employment and income, education and health. A number of general questions were also asked, for instance on cultural beliefs. These questions were based on questions asked in the CAPS panel data surveys conducted between 2002 and 2006 (Lam et al., 2008). An aspirations survey was done at the same time as the household survey. This questionnaire contained a range of in-depth qualitative questions on the women's aspirations. Shortly afterwards about 50 of the 103 women turned up to attend a life-skills course presented by myself, two students and four peer mentors for one day a week over eight weeks.10 There was a drop-out of about $50 \%$ of participants at this stage, as it became clear that a commitment of time and energy would be required. Between September 2006 and November 2009 the active women were assisted in working on one key aspiration. In April 2010, a last set of 19 interviews were conducted to assess the work the women had done on their aspirations, 11 to which material on six other active or previously active Someleze12 members whose circumstances were known to us was added, altogether amounting to the 25 women discussed in Table 2. Of the six who were added, one active woman, Fezeka, preferred not to be interviewed, two of the five had died since the beginning of the programme, one had had a stroke and could not work, one got a job and one had returned to the Eastern Cape. Phumla, one of the interviewed women, also passed away unexpectedly shortly after the interview, reputedly from a stroke. The 19 women plus Fezeka

\section{http://repository.uwc.ac.za}


are the only original members who could be traced or who were available for interviews in 2010, as many inhabitants of Site $\mathrm{C}$ had moved during the upgrading of the area in 2008 and 2009.

The question arises whether the women who worked on their aspirations were self selected with high motivation or whether they are roughly representative of the wider population. It is not really possible to determine this from our material, but it seems likely that women who are highly motivated but lacked opportunities were attracted to working on their aspirations, and that their involvement in the project in turn increased their motivation.

\subsection{The Role of the Facilitator in the Expansion of the Women's Capabilities}

Researchers can have very different roles and levels of involvement in action-research programmes, and it is important to make clear what role I had as a researcher. One of the most important inputs made by me was the life-skills course, in which the women were helped to analyse the world in which they live and worked based on some theoretical inputs, but mainly on their own life experience. Extensive small group discussions took place at this stage to facilitate reflection. They were given the opportunity to reflect on their own lives and on the potential effects of institutional constraints such as race, gender and culture on their lives and aspirations. One of the tools that were used was to draw the story of their lives as a river and to draw key moments as features along the river (Hope \& Timmel, 1984). 


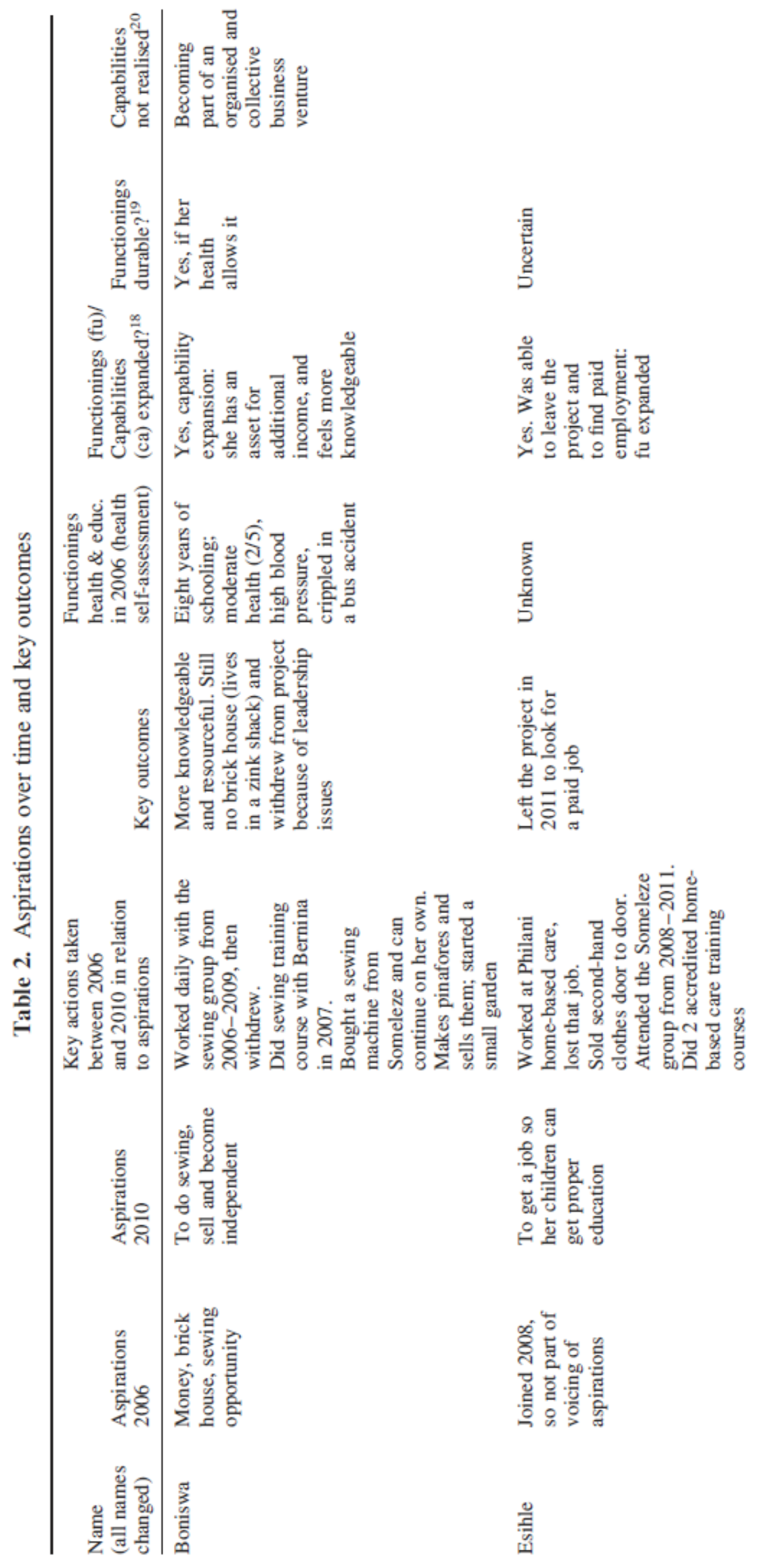




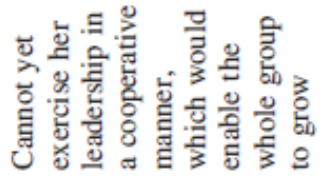

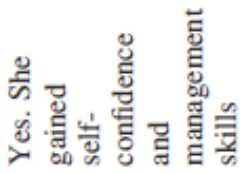

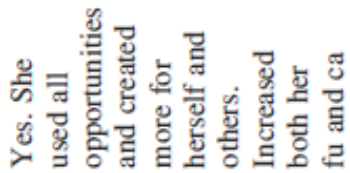

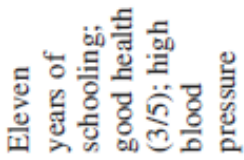

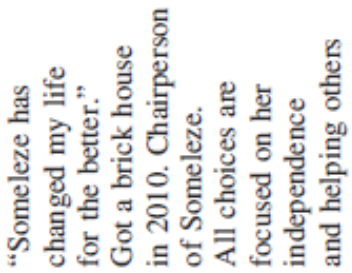

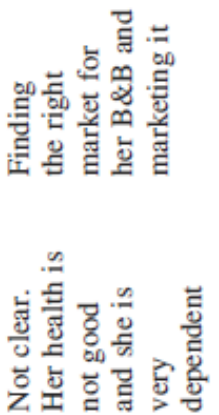

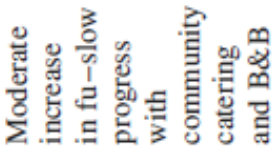

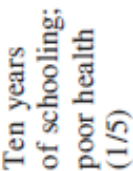

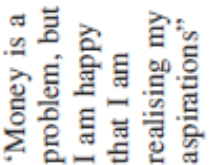

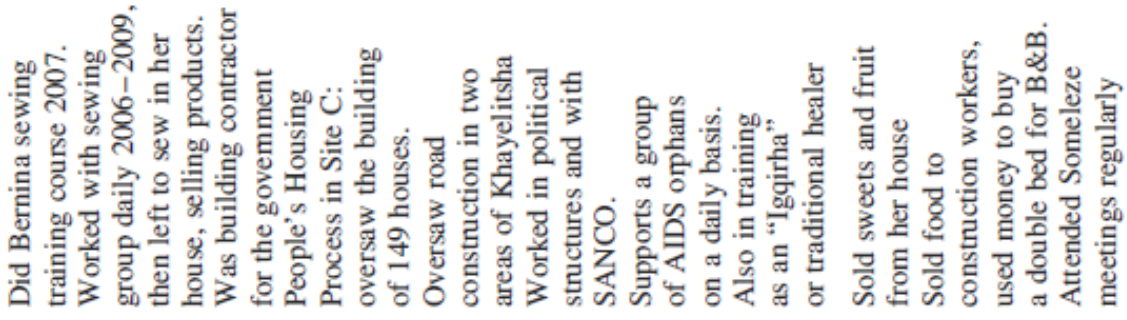

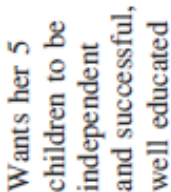

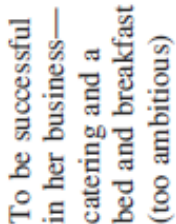

量

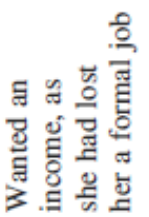

运

폼 


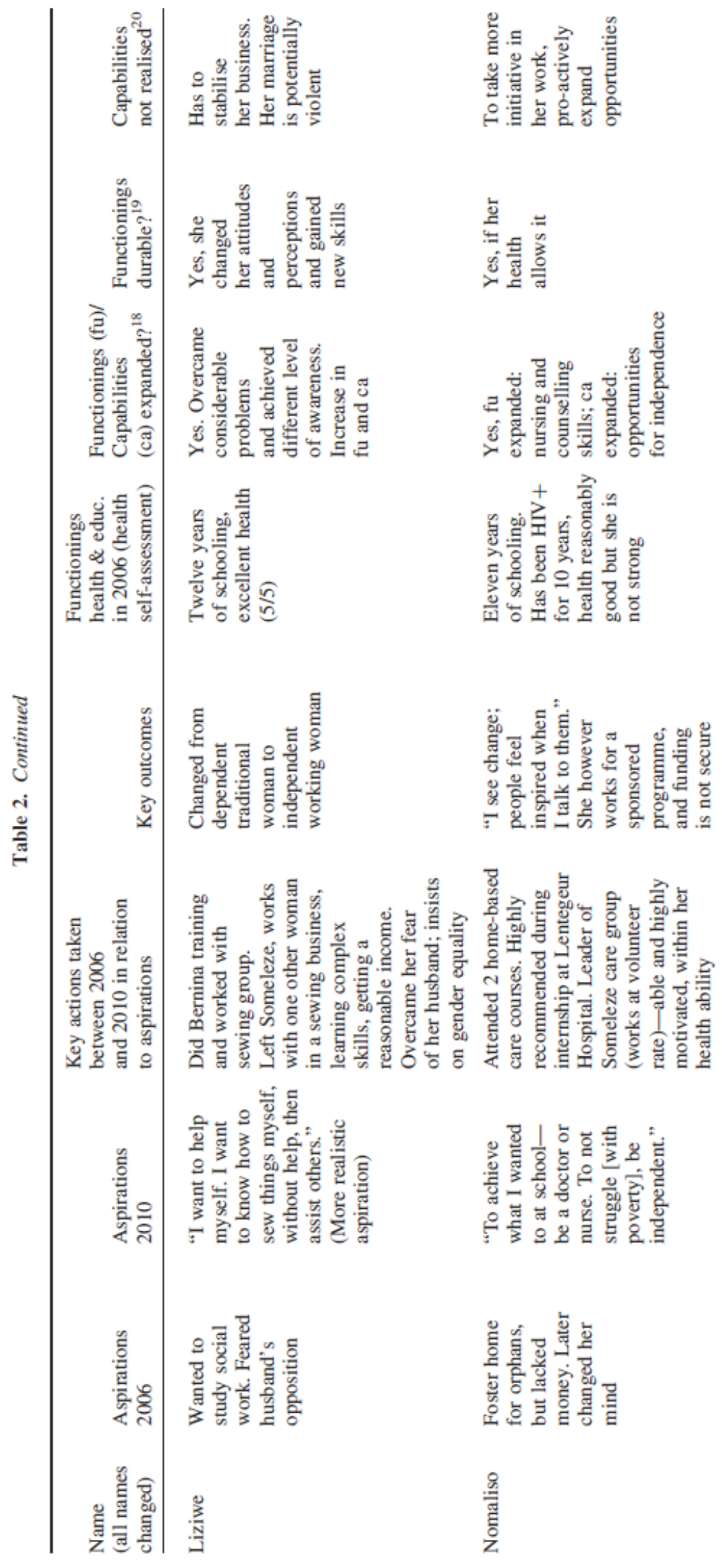




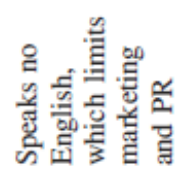

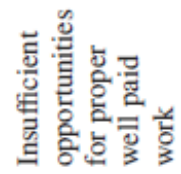

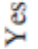

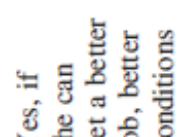

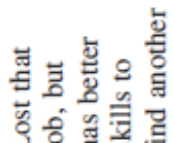

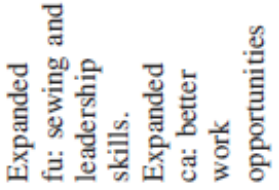

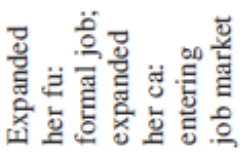

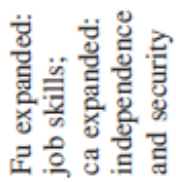

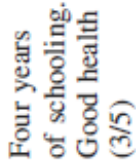

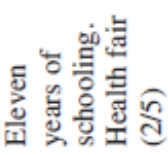

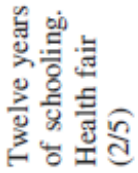

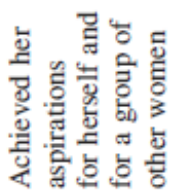

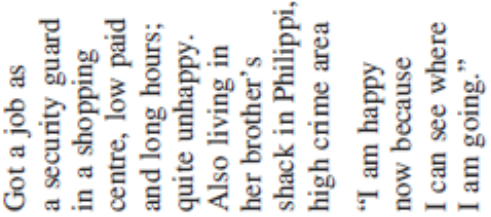

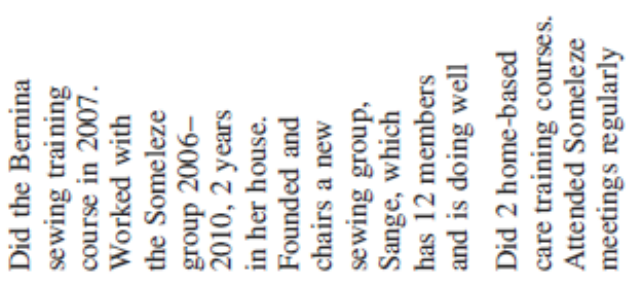

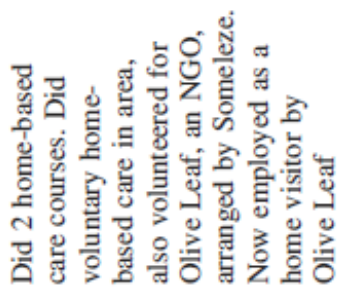

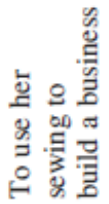

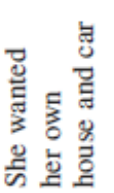

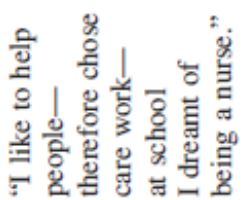

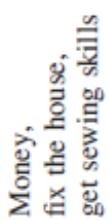

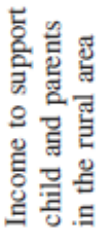

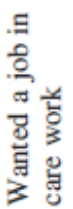

$\frac{a}{2}$

䒿

そี 


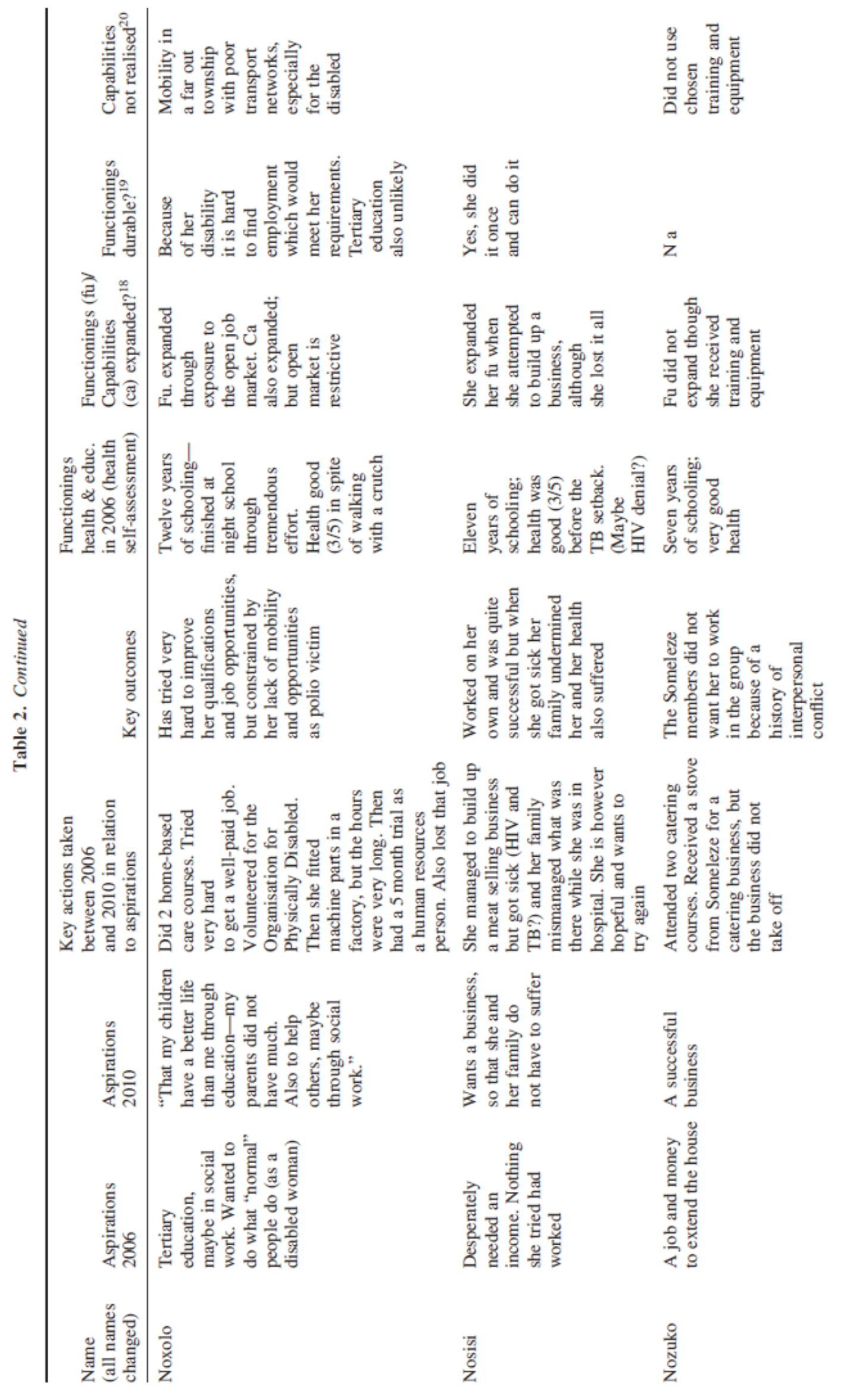




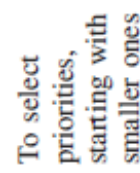

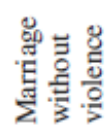

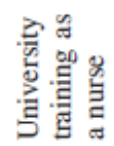

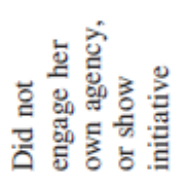

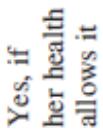

z

$\stackrel{0}{0} \quad$ z

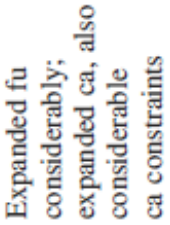

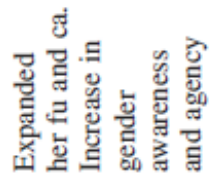

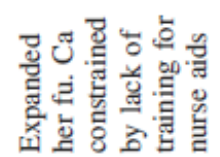

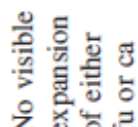

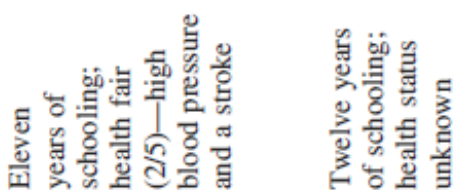

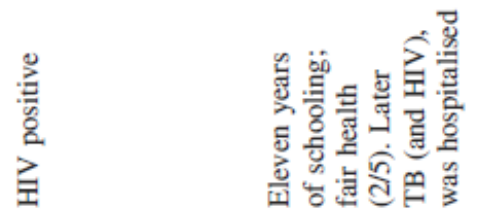

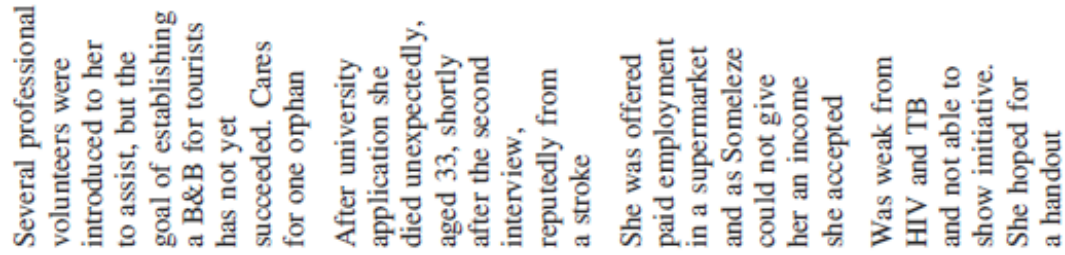

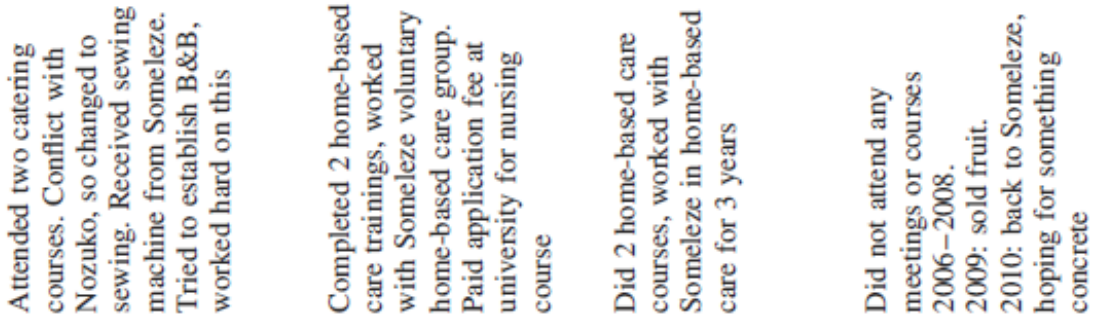

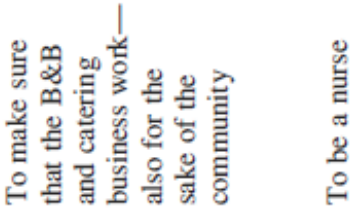

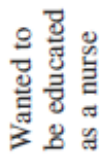

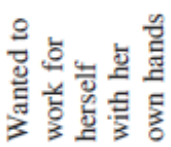

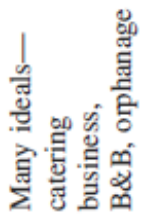

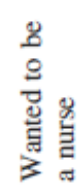

20.

홍. 혼

总就

点语部

$\frac{\sqrt{5}}{0}$

章

蛋

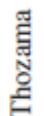




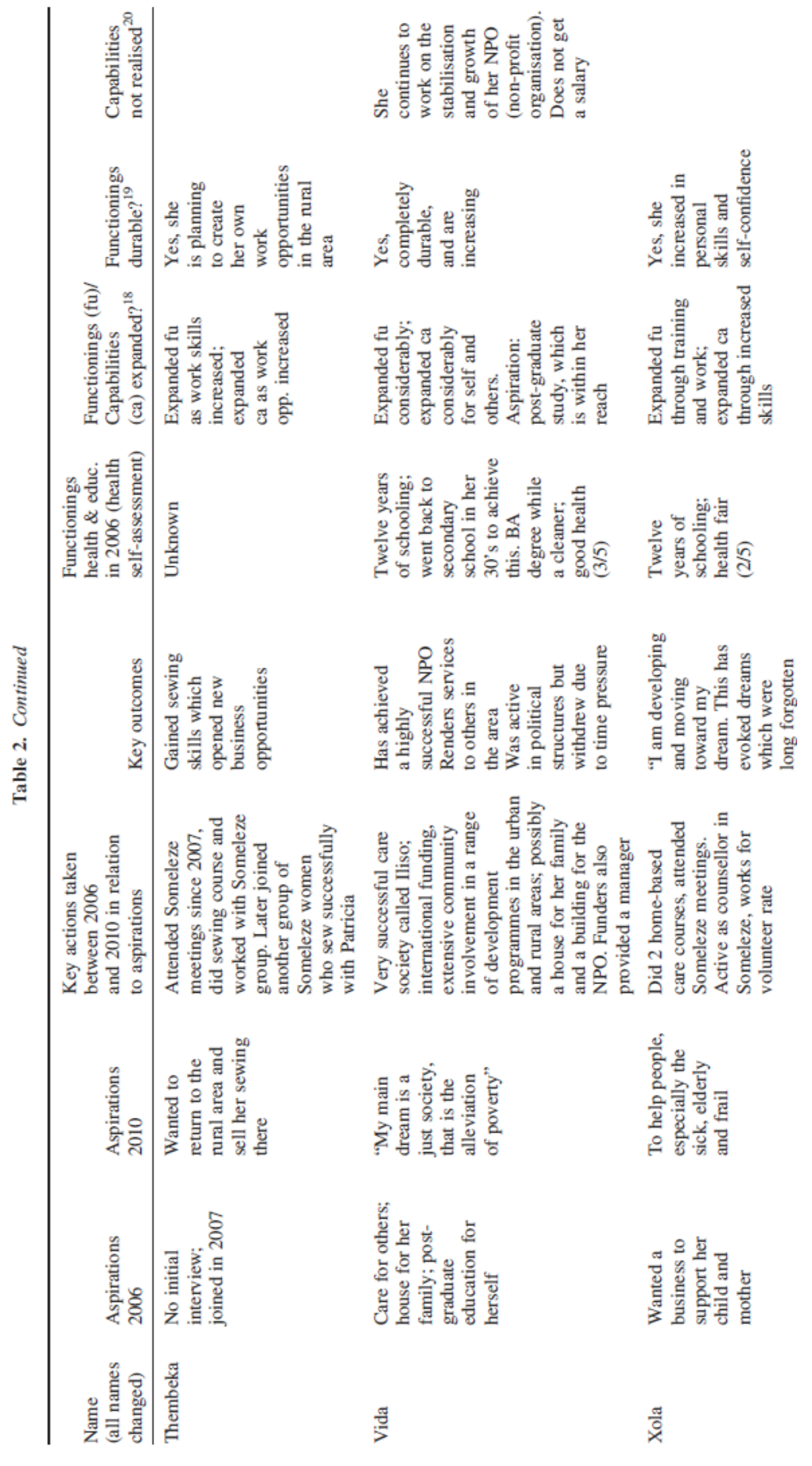




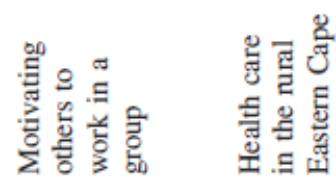

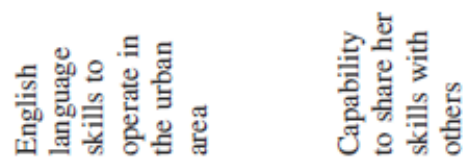

$\mid$ ฐี๊

$\stackrel{0}{\circ}$

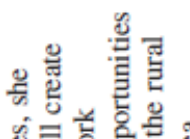

咅

乙

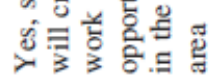

通学

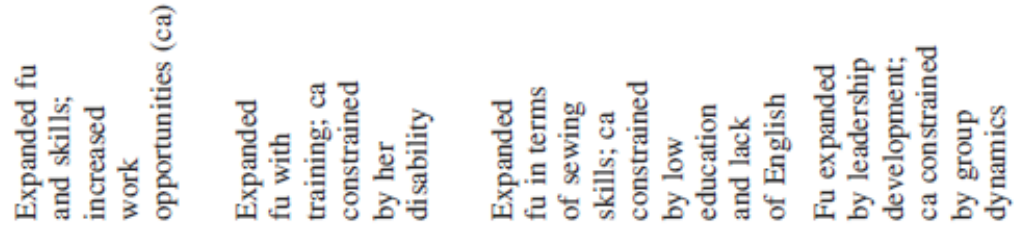

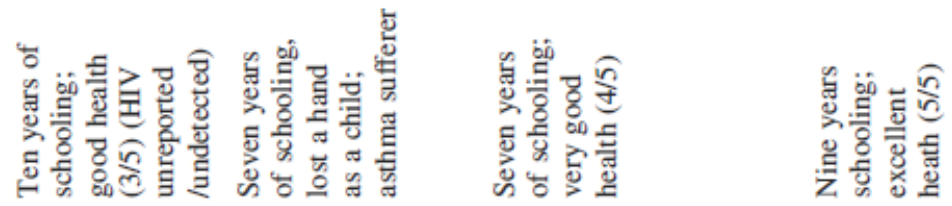

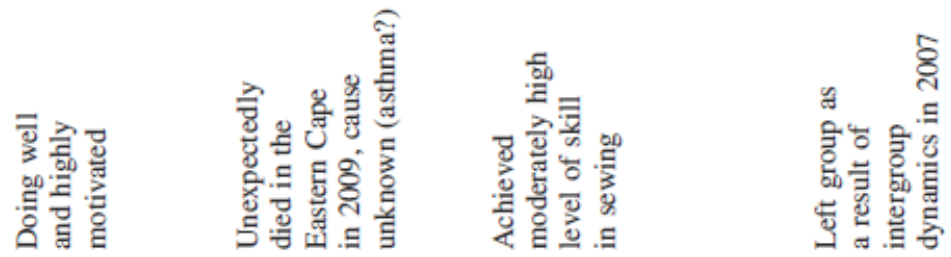

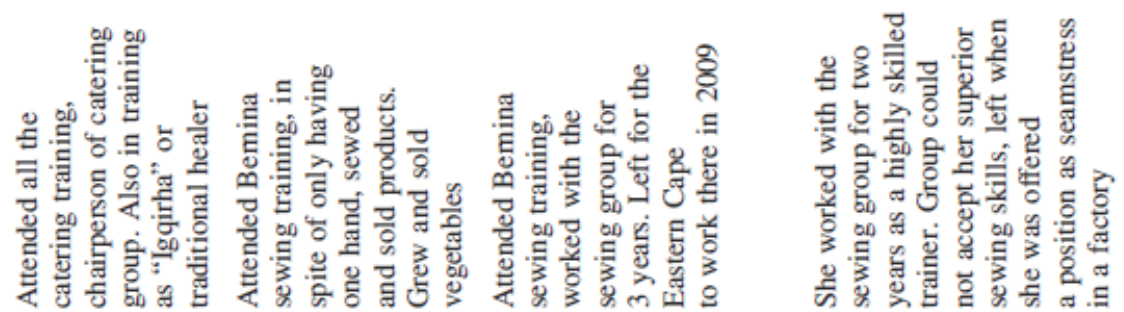

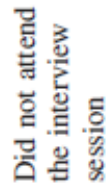

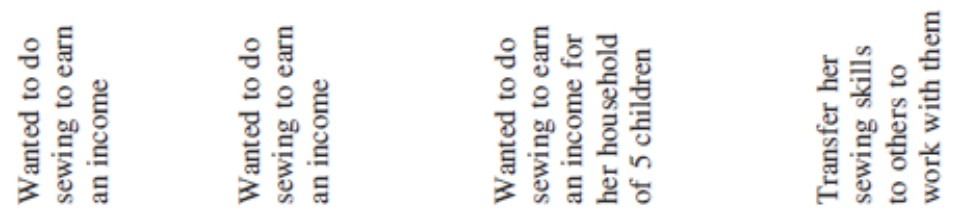

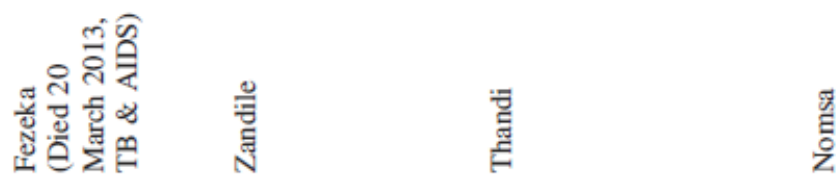




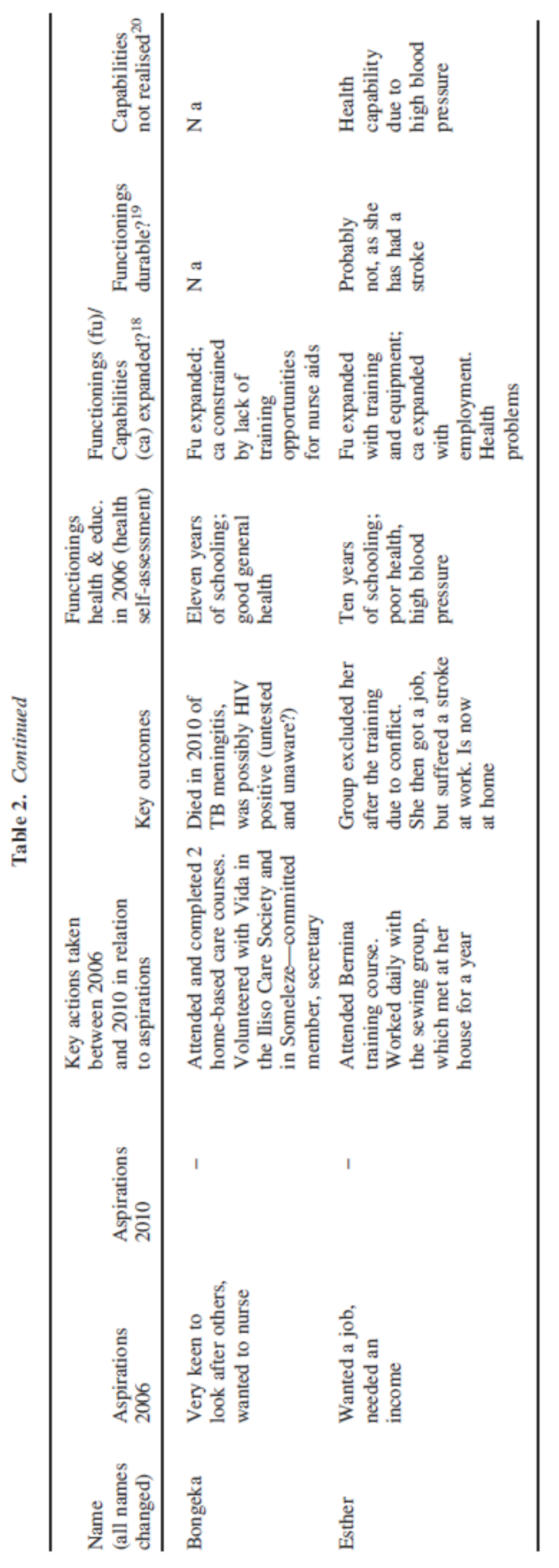

http://repository.uwc.ac.za 
These biographical narratives were used to build cohesion and trust between the women to develop social and personal insight into the forces which impact their lives and as a basis for future planning based on their aspirations. At this time I undertook to make a connection for each individual woman with a community organisation which could possibly assist her in working on achieving her aspirations. I had made the false assumption that the women would want to work individually, and a number of organisations had provisionally agreed to take one or two women into their existing programmes for short training periods. When, however, the women chose a number of collective activities including the idea of working together in a women's centre, it was clear that this strategy had to change. By means of fundraising13 enough resources were found to construct a small women's work centre out of two shipping containers, 15 women were provided with sewing machines and basic sewing training, 12 women were trained and mentored as caterers, 3 received training in hair braiding and 15 women received training in home-based nursing care. This commitment to find resources consequently formed an inherent part of the research, which had the limitation that my role was not just that of researcher14 (see discussion on limitations of the research below). In 2010, training sessions took place once a week for 10 weeks to develop their business and networking skills. Volunteer helpers and trainers were also introduced to the group throughout this period to increase their very limited business opportunities.

As facilitator/researcher I assisted the group in reflection during regular meetings, so that the choices they made would reflect their own, considered aspirations. In addition, the formal training sessions aimed to assist them in understanding the nature of the world of work, both in terms of social and business dynamics.

\subsection{The Role of Government in Extending the Women's Capabilities}

As this was a period with intensified inputs by government, particularly on housing, the participating women were able to benefit from these in addition to being involved in Someleze. Government [national, provincial and local] had made a number of contributions to the capabilities of the women involved during the period 2006-2010. Twelve households received social grants, either a small child care grant of R250 per child per month for each child under sixteen 15 or a disability grant of R1080 per month. Two other households had received new brick houses, with water and electricity inside the house. Three further households had received both grants and a house. Four households had received neither grants nor houses. The five women who received new houses reported that it made an immense difference to their lives. They were now able to use the house as an asset, as work space, and as a safe and comfortable base for their families.

In the area where the programme is located there is moreover a multi-purpose clinic, there are schools and most government departments can be accessed, although not always easily. Anti-retroviral drugs are now available at the clinic for the three members of the group who are known to be HIV-positive, but were not distributed within the public health system before November 2003. The most important role of government may have been in preparing people for employment. However, the participating women suffered from the weak education 
system of the apartheid era (Van der Berg, 2008) and consequently did not have the skills or qualifications which would have enabled them to achieve the standard of living they aspired to.

\section{Results and Analysis of the Fieldwork: Aspirations and Key Outcomes}

The most important research task throughout was to assist the participating women in articulating a well-considered aspiration, and then to support them as they worked on it. As can be seen in Table 2, the women initially had a number of aspirations, which differed from person to person, but when they had to select one to work on they collectively decided to work on an aspiration which could potentially generate an income. In presenting and analysing the results of the work on aspirations, the following questions will be addressed: What shaped the women's aspirations? Did their capabilities increase and was the increase that occurred directly related to their work on aspirations? What were the constraints on their initial aspirations? To what extent were these aspirations realistic, and was there any evidence of adaptive preferences? Lastly, what role did their own agency play in this whole process? The limitations of the research will be reviewed and the conclusions will be discussed.

\subsection{What Shaped the Women's Initial Aspirations?}

The women were influenced by the context in which they live, a large-scale urban settlement which receives internal migrants in search of better opportunities. They are all first generation migrants who were born in the rural Eastern Cape, and who have close and ongoing contact with family members and home communities in the rural areas where they come from. In this way they have been shaped by the cultural norms which these communities hold, and which gradually change with exposure to other values as different ideas emerge about "the good life" (Appadurai, 2004, p. 67).

Their physical relocation to the urban area can be seen as an attempt to obtain better access to resources and opportunities. It can also be seen as a way of improving their class position. As Francis, the leader of the group, observed in 2007, "We want to go from being the poorest of the poor, to being somewhere in the middle." Steinberg (2011) postulated that this deep aspiration to join the security of the middle class is a prominent theme in South Africa at the moment, with Affirmative Action opportunities and the visible upward mobility of those who have become integrated into the economic system. I would argue that this ideal, expressed by the leader of the women's group, represents a powerful collective aspiration.

Their gender position also shaped their aspirations; as women they were limited in their ability to act while they lived in the rural area and were free to explore different income and lifestyle options in Cape Town-in fact, in a focus group discussion they said that this was one of the important reasons they came to the urban area (Conradie, 2009). The women in this group embraced the new freedom to think and act more freely and it is reflected in the degree of agency they engaged in. They repeatedly spoke about this freedom and how they themselves influence the gender norms in the rural areas when they visit.16 
Their aspirations were however primarily constrained by their economic position and by their need for a sustainable regular income, as it is evidenced by the aspirations they chose to work on. The question is again whether the cultural norms which they assimilated have influenced their capacity to aspire to a different life. In order to be able to explore this more comprehensively the aspirations which the women expressed in 2006 and again in 2010 will firstly be reviewed, as well as the key outcomes of their work on these aspirations. The information is summarised in Table 2.

The February 2006 survey contains the benchmark data against which the women's achievements can be assessed. Eighteen out of 25 responses in the long interview in $2006^{17}$ indicated that the women wanted an income or a job of some kind, which shows clearly that the majority wanted the means with which to secure a livelihood, whatever other aspirations they had. If one takes into consideration that the five women who wanted to do care work [either as home-based carers or by fostering orphans for payment] might also have wanted to do that as something which they would enjoy doing but which could simultaneously provide an income, it would mean that everyone except two women had wanted an income as their main aspiration. Four mentioned the improvement of their house, or acquiring a new house as a further aspiration. Did these aspirations reflect realistic possibilities and did the capabilities to realise them exist for these women, or did they adapt their preferences, maybe because of a lack of the capacity to aspire? These questions will be addressed in turn below, but we shall start by examining whether there had been an increase in functionings and capabilities.

\subsection{Did Capabilities Increase, and was This Related to the Work on Aspirations?}

This question is central to the research and will be mainly answered with reference to the responses to the second questionnaire, on the achievement of aspirations. This questionnaire was used for a last set of interviews with 19 of the 25 women who had remained active throughout the action research period.

The increase in the women's functionings between 2006 and 2010 is given in summary form in column 7 of Table 2. In all but two cases there were increased functionings which were directly related to aspirations expressed in 2006, and in one case in 2008. These new functionings range from minor actions such as attending a training course and joining a group of women who were working for themselves, to looking for ways to acquire new skills and business outlets. I initially tried to differentiate between those who had gained much increased functionings and those whose improvement was more marginal. Over time I however realised that this was not a linear process, and that their position in relation to market activities is so precarious that things can change within a short period of time for better or for worse. Somebody like Noxolo who had seemed to have gained much in 2010 when she got a good job in the formal sector was later disadvantaged by market conditions. She lost her job and is now working with Someleze again. Ntombi achieved her lifelong aspiration by getting a job as a home visitor in a health NGO, and then the NGO lost its funding base and retrenched all the home-based care workers in 2011. 
In some cases a deep inner change occurred, and a woman would free herself from previously restrictive cultural conditions. Liziwe, for instance, had this to say:

If this programme did not come, I would not have started to dream. It changed my life, from my culture and family, also my new family, my husband and his mother. I had to stay at home, clean, wash, cook. So you came, you told me, so my mind must open. You said: can you do things? I said yes, without my husband. Also without my family. Sometimes that was difficult. I thought my husband would slap me. Then I said to him: I am going, so slap me. I am waiting for you to hit me. Then he did not. Now it is easy to go to work. I make men's trousers. My husband said: you can't make that! I said: I can. He is jealous and thinks I will have an affair. I am so busy, I think about life, what I can do, I don't have time for affairs. It is 2010 now, and I think it will soon be 2013-where will I be then? (Liziwe, personal interview conducted on 26 May 2010)

Even in Liziwe's case, however, things changed in 2011 when she was involved in a bus accident on her way to a funeral in the Eastern Cape, and had to spend some time economically inactive while she recovered.

Table 2 contains three more columns on functionings and capabilities. In column 6 health and education functionings are summarised as they were reported in 2006. Both of these sets are instrumentally of key importance (Sen, 1999, p. 10) as can be seen from some of the examples in Table 2. Being crippled in a bus accident or being HIV positive has a negative impact on one's ability to exercise choice, as does a low level of formal education. These health and education functionings were taken into account when the expansion of functionings was assessed (column 7). The question was then also asked whether the new functionings would be durable. In fifteen out of 25 cases they were, but this is an assessment based on the women's situation during a specific time slice. As argued above, things can change and in a few years' time such an assessment might look quite different. Lastly the question was asked which capabilities had not been realised, and once again the researcher made the assessment based on available information and on observation over the period of involvement.

In the 2010 interviews a question was asked on important decisions and choices the women had made over the previous 4 years. This question seems to have evoked the most meaningful responses. While the other questions rendered a list of activities of things that the women had achieved, the question on choices and decisions gave the following qualitatively different responses:

I decided to work for myself as I won't get anything sitting down. (Noxolo, interviewed on 30 April 2010)

In these four years I realised what I want in my life and have seen that my family also supports me. I have also discovered that I can be whatever I want to be if I put my whole 
strength into it. Without thinking about my aspirations I would still have been sitting in the sun every day. (Phumla, interviewed on 30 April 2010)

These responses seem to be related to a determination to persevere and to attempt what had previously seemed too difficult. This is also evident in the perseverance of the women over a five year period, often with very little sustained success. The new functionings are therefore associated with decisions and choices, which in turn led to different actions, such as "I did beadwork, sewing or catering, and gradually built up a small business" or "I attended a number of courses and improved my skills”.

When the women formulated their aspirations again in 2010 they did so in different terms, on the whole more realistically, and also with a strong reference to self-reliance. Some of these responses were, for instance:

I want to sew and sell and have financial independence. (Boniswa, interviewed on 30 April 2010)

I do not want to struggle, I want to be independent. (Nomaliso, interviewed on 30 April 2010)

I want to work for myself. (Thozama, interviewed on 29 April 2010)

Two women who had in fact increased their incomes considerably during this time, Francis and Noxolo, wanted to make sure that their children would be well educated, independent and successful. Five more wanted to care for others. Interestingly this last number had stayed almost constant from the start. One of them, Vida, said that having established a large care society for the people of her area during this period, her main aspiration now was to work for "a just society" in which poverty was increasingly overcome.

In conclusion it is therefore clear that for all but two of the women the process of involvement in thinking about articulating and working on their aspirations had brought about increased functionings, and in some cases a different approach to challenges. It is of course possible that these changes would have happened anyway. For these women they had not occurred before, however, and it is likely that the conscious reflection and deliberation on their lives and ideals, as well as the opportunities offered by the programme, played a role in their increased functionings.

\subsection{What were the Constraints on Their Initial Aspirations, and were the Initial Aspirations Realistic?}

The initial aspirations of the women were strongly shaped by their lack of means to fulfil the basic needs of their families. They were living at a very basic level and wanted to improve this. A better income was, however, not the only consideration, as becomes clear when the individual aspirations are examined. A large number voiced quite ambitious aspirations. This could be the outcome of a period of expanding opportunities in South Africa, with political

\section{http://repository.uwc.ac.za}


change, political promises, cultural change such as more gender equity and the experience of "a moment of possibility" as a result of South Africa's recent history.

The question then arises to what extent the initial aspirations were realistic and built on already existing capabilities. In all cases the aspirations voiced were those which the women had not been able to achieve on their own and for which they needed some resources and some assistance with opportunities and ideas. Eight of the 25 women voiced aspirations which turned out to be too ambitious, rather than adaptive, given their specific situation at that time (see Table 2, column 2). All eight managed to achieve some functionings which were either a step in the direction of their aspiration, or something simpler which nevertheless improved their situation. Francis wanted to be a "fashion designer" but became a competent seamstress; Hazel and Patricia both wanted to have a guesthouse for overseas tourists but turned instead to catering for the local community.

The other five all wanted to go to university, but attempted an income generating activity instead, or in one case (Noxolo) obtained a job, which she lost again. The women who had not had too ambitious aspirations all achieved some functionings which enabled them to have at least a small income. The conclusion can therefore be reached that eight of the women had voiced an aspiration that was above their ability and resources, while the others had expressed a more achievable aspiration.

Their capacity to "navigate" and negotiate for change was moreover limited by a lack of political and other experience. There is a reasonably good political infrastructure in Site $\mathrm{C}$ in Khayelitsha (Thompson \& Conradie, 2011), but only some of the women, like Francis and Vida deliberately became part of this system in order to achieve their goals. Because many of the women's previous efforts had been unsuccessful they did not know how to start to address their personal aspirations. The women are also aware that others who had broken out of the poverty cycle had mostly done so by means of a better education, and this was therefore a strong aspiration for five of the women, who knew that a better education would change their terms of recognition. Their poor housing conditions, with the majority living in shacks and many lacking even a basic toilet, served as a further driver for change. If we return to Appadurai's statement (2004, p. 68), that the concrete, expressed needs form a visible inventory which can lead us to forget that something might lie beyond, we are reminded that what the women expressed is in all likelihood only a first level of aspirations, the means of change and that they probably envisage an improved life for themselves and their children within the concrete goals they have achieved.

\subsection{What Evidence is there for Adaptive Preferences?}

We are now in a position to examine whether any of these women had exercised adaptive preferences. The evidence seems to point rather in the opposite direction, namely thatmany of them were too ambitious in their goals, and had possibly adapted their preferences upwards. It also seems that they did not sufficiently understand what would be required for them to achieve these aspirations. Two of the women set out to have a bed and breakfast, and had as rolemodels a number of township women who had done so successfully: two of whom, 
Vicky and Lydia, acted as peer mentors in the life-skills course in 2006. There were however problems which had been difficult to foresee: the quality of the buildings and of furniture and linen which would be required, the difficulty of marketing their guest houses when there was an economic slump worldwide and many others. Professional women offered to assist as volunteers, but this goal nevertheless turned out to be too ambitious for the two women involved. They haven't given up, but are both trying to raise funds by means of selling food.

In the case of the women who wanted to study it also seemed that they had aimed too high. Two wanted to do social work and three wanted to study nursing. All but one had finished the last year of school, but whereas some universities such as the University of the Western Cape attempted to take in as many previously disadvantaged students as possible in the post1994 period, entrance qualifications have now been tightened considerably and their school grades are unlikely to allow them university access. They might therefore have to repeat their school end examination in an effort to get better grades. The one who had previously failed grade 12 would have to sit for it again, and then apply for university admission. If admitted, they would have to find the R100o needed for registration and would have to apply for a government scholarship for their studies, which would in all likelihood be granted. Moreover, if admitted, the next few years of their lives would be difficult, as they all have small children, and they would be without an income and would need money for transport and other expenses. They would therefore probably have to do some paid work in addition to studying and caring for their families. It therefore seems safe to conclude that going to university is not a very realistic aspiration in this context.

However, Vida, who had been successful in her aspirations to establish a Care Society, had done just that, although her first child, who was severely handicapped and died later, had been in her mother's care at the time when she decided to improve her life. She enrolled in secondary school again when she was in her thirties, wore a uniform with the children and obtained a good school end certificate, while she was working as a part-time cleaner in a hotel. One of the hotel guests heard her story and gave her some money, which she used to enrol for a BA degree, in which she was successful, whilst working throughout. She only married and had another child when she had completed her studies.

It thus seems that there is no evidence of adaptive preferences in this programme, but rather of considerable obstacles to the achievement of all aspirations, due to historical and institutional constraints in the South African context. This did not prevent the women in this study from attempting to achieve parts of their aspirations in a step-bystep process. It might also be that focusing on their aspirations had led to an upward adaptation, as described by Clark (2009), where exposure to the idea of what might be possible had led to higher aspirations than what they would otherwise have had, or what they could reasonably expect to be able to realise.

\subsection{The Role of Their Own Agency in Achieving Their Aspirations}

The largest part of the breakthroughs that the women experienced was undoubtedly due to their own efforts, and the ways in which they were able to use what I and 
the various funders I accessed offered them, in training and small economic and other opportunities.

Through using their own agency, 23 of the 25 women were therefore able to increase their capabilities. Their agency is seen particularly in their strong determination to succeed. The increased agency of most of the women is arguably one of the most important consequences of this action research-something which gave them the determination to keep trying until they succeed and also to be judicious in how they spend their energy and resources. This nevertheless did not enable them completely to break through the historical barriers which restrict their progress. For this to change, larger structural and social changes would have to take place. This is consistent with the view of agency as that which is possible to achieve within the boundaries of structural opportunities and constraints (Giddens, 1979, 1984; Bourdieu, 1990, 1977; Sen, 1999).

Twenty-three of the 25 women listed in Table 2 had increased their functionings and articulated their aspirations in new ways. They thus illustrated how new functionings can lead to new aspirations, in a dynamic and potentially continuous process. The women have however been constrained throughout by a number of factors. Their gender position, their racial position in apartheid South Africa and beyond, their class position as an unemployed underclass and some of the cultural norms under which they grew up, all denied them the full range of their potential capability set.

It is possible to therefore conclude that the voicing of and working on aspirations can activate agency, and the ability to sustain commitment over longer periods. The women had to engage deeply with their own lives and futures. They stated that it gave them a sense of direction and purpose, even when there were many obstacles. They also said that they had decided on new activities that would help them to change the direction of their lives. The words of the women often seemed unrealistically optimistic in comparison to their real-life experiences, but they expressed determination and commitment. "I will never give up" was said in many different ways by different women (Conradie, 2008). During the life-skills course in 2006 I asked the women to formulate a central goal for themselves. Autonomy, or being accountable to themselves, and independence were mentioned as important by almost everybody. This goal remained central throughout the programme.

\section{Limitations of the Research}

The first and probably the most significant limitation of the research was the fact that I was an outsider, both in terms of the women's culture and language and as a white researcher in a black area. I always worked with an interpreter, and as an external interpreter was not always available, the women in the group who could speak English would translate my English into isiXhosa. This meant that the translator could potentially dominate the group. I also did not always manage to understand the nuances of different situations, as much was lost in translation-both literally and in terms of customs and those unstated "codes" which

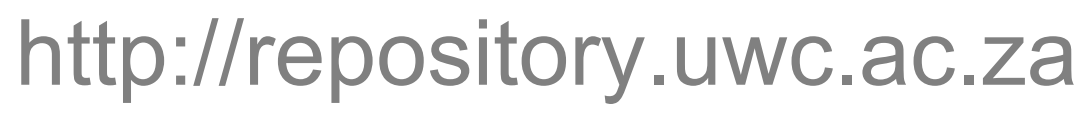


people in a particular cultural group adhere to without necessarily being conscious of it. One of the women, Vida, once said "Our custom is not to say things directly." That alerted me to the many ways in which things can be said, or implied, indirectly.

Nevertheless, I am a South African with an understanding of the broader society. I have also been involved in development work and research in Khayelitsha since shortly after it was founded and in other townships in the Western Cape for more than three decades. A second limitation is linked to the fact that I made a commitment that I would find a number of resources for them, for training and equipment. This was a "noise" factor in the research, as one can never be certain whether information was given in order to obtain resources or not. On the other hand those who only came for the resources probably did not stay long when they realised that their progress would depend on themselves.

A third and last limitation of the research is the fact that it is not possible to be certain that the women might not in any case have changed, for a different reason than having voiced and worked on their aspirations. It might for instance have been the upgrading of the township that motivated them to uplift themselves and to aspire to a more rewarding way of life. The women's own words nevertheless indicated that the steps they had taken had been linked directly to the voicing of their aspirations, although many indicated that the upgrading of the township had also played a major role in improving their lives.

\section{Conclusion}

If we return to Appadurai's notion that aspirations can play a role in the field of poverty and development, it was seen that the women in this group were able to change their material circumstances, albeit to a limited degree, in part by voicing and deliberately working on their aspirations. They also gained in self-confidence and in having an increased sense of autonomy. Some of them, about a third of the group, voiced aspirations which seemed overly ambitious for their circumstances and personal abilities, and they could be said to have upwardly adapted their aspirations, as suggested by Clark (2009). It could however also be argued that the structural and institutional obstacles in South Africa, such as the inadequate education system, are so pervasive that some African township women lack the capabilities to achieve the aspirations they had decided to pursue. This would imply that realisation of the aspiration of improving their income and thus their class position is obstructed by inadequate education. The obstacles might also include adverse terms of recognition, in Appadurai's language, and the ways in which their particular identity and class stigma is constructed by others.

It was nevertheless seen that assisting women in a slow, continuous, deliberate and step-bystep process of discovering, voicing and formulating their aspirations and then offering limited opportunities to deliberately work on these acted as a strong motivating force to engage in their own development. In this process 23 out of 25 women had gained new functionings and extended their capabilities. As they did so, there was a gradual and sustained increase in their motivation. Facilitation was needed for this process and numerous capability obstacles had to be addressed. Although not all had achieved what they 
started out to do, and some had set themselves very ambitious goals, many of the women seem to have made a determined decision to pursue their own aspirations.

Thus we can conclude that assisting the poor in a deliberate, self-directed process to work on their aspirations over time can increase capabilities and activate agency. It is nevertheless constrained by the structural opportunities available within the specific context. Furthermore, on the basis of this single action research programme we cannot conclude that this is a universal strategy which would fit into every poverty-reduction programme.

\section{Notes}

1 Mercier P. Night Train to Lisbon, Atlantic Books, 2004.

2 The actions taken by the women in support of their aspirations are listed in greater detail in Table 2, column 4.

3 In Khayelitsha, there is a wide network of consultative structures (see Thompson \& Conradie, 2011).

$4 \mathrm{Mr}$ Sogayise, the former chairman of the Khayelitsha Development Forum, maintains that this is the estimate which is used for the planning and rendering of services in Khayelitsha, although the census figures for 2001 and for 2011 are much lower, due to the difficulty of counting people in informal settlements.

5 These figures emerged from a household survey conducted with the participating women in February 2006-see Table 1.

6 In 2006, the annual average exchange rate for the South African Rand was: R100 $=\$ 14.78$ $=€ 11.75$.

7 This was the value of the child care grant in 2006.

8 SANPAD is the South African-Netherlands Research Programme on Alternatives in Development. The author has been the researcher and facilitator of the action research programme. Prof. Ingrid Robeyns of the Erasmus University Rotterdam acted as the SANPAD Dutch research partner between 2007 and 2010.

9 Apart from this action research programme, I have intermittently been active in Khayelitsha in training and research since 1987.

10 The aims and practices of the life-skills course will be explained in detail in the next section.

11 I am particularly indebted to Pamela Tsolekile and Nombuyesile Dziba for assisting in conducting and translating the interviews.

12 Someleze is the organisation which was formed by the women for those who wanted to work on their aspirations collectively. It means "we strengthen each other".

13 Very valuable assistance was received from the Quaker Service in Cape Town.

14 An external trust was founded to deal with financial matters, with professional and reputable trustees.

15 This was the amount of the child are grant in 2010, and the age of the children who qualify had been increased.

16 The ways in which gender relations limit their lives were also evident when Vicky Ntozini, a peer mentor and inspiration for the whole project, was murdered by her husband in their house in Khayelitsha in November 2012. 
17 See Section 5.1 for an explanation of how many women participated in the different phases of the research, and how the 25 women who were assessed were selected.

18 The question asked here is whether she has extended her repertoire of beings and doings, and therefore her future opportunities.

19 The next question is whether these beings and doings could be repeated in future. 20 This column refers to opportunities she clearly did not make use of. 


\section{References}

Alkire, S. (2008) Using the capability approach: prospective and evaluative analyses, in: F. Comim, M. Qizilbash \& S. Alkire (Eds) Capability Approach: Concepts, Measures and Applications (Cambridge: Cambridge University Press), pp. 26-49.

Alkire, S. \& Deneulin, S. (2009) The human development and capability approach, in: S. Deneulinand \& L.

Shahani (Eds) An Introduction to the Human Development and Capability Approach: Freedom and Agency (London: Earthscan), pp. 22-48.

Appadurai, A. (2004) The capacity to aspire: culture and the terms of recognition, in: V. Rao \& M. Walton (Eds) Culture and Public Action (Stanford: Stanford University Press), pp. 59-84.

Ashforth, A. (1996) Of secrecy and the commonplace: witchcraft and power in Soweto, Social Research, 63(4), pp. 1183-1234.

Berger, P. \& Luckman, T. (1966) The Social Construction of Reality (London: Allen Lane).

Bourdieu, P. (1977) Outline of a Theory of Practice (Cambridge: Cambridge University Press).

Bourdieu, P. (1990) The Logic of Practice (Oxford: Polity Press).

Bundy, C. (1988) The Rise and Fall of the South African Peasantry (Cape Town: David Philip).

Burchardt, T. (2009) Agency goals, adaptation and capability, Journal of Human Development, 10(1), pp. 3-19.

Castells, M. (2004) The Power of Identity (Malden, MA: Blackwell Publishing).

Clark, D. (2009) Adaptation, poverty and well-being: some issues and observations with special reference to the capability approach and development studies, Journal of Human Development and Capabilities, 10(1), pp. 21-42.

Clark, D. \& Qizilbash, M. (2008) Core poverty, vagueness and adaptation: a new methodology and some results for South Africa, Journal of Development Studies, 44(4), pp. 519-544.

Cole, J. (1987) Crossroads, the Politics of Reform and Repression, 1976-1986 (Johannesburg: Ravan Press).

Comim, F. (2008) Measuring capabilities, in: F. Comim, M. Qizilbash \& S. Alkire (Eds) The Capability Approach: Concepts, Measures and Applications (Cambridge: Cambridge University Press), pp. 157-200.

Conradie, C. M. (1991) Khayelitsha: Interpreting a process of social transformation, Thesis submitted for the Master of Arts in Development Studies, University of the Western Cape.

Conradie, I. (2008) Agency and capabilities: personal history, capacity and developmentoriented agency in a development programme in Khayelitsha, Cape Town, Paper presented at the HDCA Conference, New Delhi.

Conradie, I. (2009) SANPAD Research Report. Enhancing Selected Life-skills as a Key to Development: Addressing the Aspirations of Poor Women in Khayelitsha (20062009), Institute for Social Development, University of the Western Cape.

Du Toit, A. \& Neves, D. (2008) Informal Social Protection in Post-Apartheid Migrant Networks: Vulnerability, 
Social Networks and Reciprocal Exchange in the Eastern and Western Cape, South Africa, Working Paper 74, BWPI, http://www.bwpi.manchester.ac.uk/resources/WorkingPapers/bwpi-wp-7409.pdf

Du Toit, A. \& Neves, D. (2009) Trading on a Grant: Integrating Formal and Informal Social Protection in Post-Apartheid Migrant Networks, Working Paper p. 75, Brooks World Poverty Institute.

Fanon, F. (1986) Black Skin, White Masks (London: Pluto Press).

Giddens, A. (1979) Central Problems in Social Theory: Action, Structure and Contradiction in Social Analysis (London: Macmillan Press).

Giddens, A. (1984) The Constitution of Society (Cambridge: Polity Press).

Giddens, A. (1991) Modernity and Self-Identity: Self and Society in the Late Modern Age (Cambridge: Cambridge University Press).

Giliomee, H. \& Schlemmer, L. (1985) Up Against the Fences (New York: St Martin's Press).

Goldin, J. (2011) From vagueness to precision: raising the volume on social issues for the water sector. Paper presented at the 9th International Conference of the European Society for Ecological Economics, Istanbul.

Hacking, I. (1999) The Social Construction of What? (Cambridge, MA: Harvard University Press).

Hope, A. \& Timmel, S. (1984) Training for Transformation, Vol. 1 (Gwero: Gwero Press).

Ibrahim, S. (2006) From individual to collective capabilities: the capability approach as a conceptual framework for self-help, Journal of Human Development, 7(3), pp. 397416.

Lam, D., Ardington, C., Branson, N., Case, N., Leibbrandt, M., Menendez, A., Seekings, J. \& Sparks, M. (2008) Cape Area Panel Study Waves 1-2-3-4 (University of Cape Town), http://www.caps.uct.ac.za/index.Html

Leibbrand, M. (2010) Trends in poverty and unemployment in South and Southern Africa, Social Policy Forum workshop on Social Protection, UWC, Cape Town.

Nussbaum, M. (2000) Women and Human Development: The Capabilities Approach (Cambridge: Cambridge University Press).

Qizilbash, M. (2009) The adaptation problem, evolution and normative economics, in: K. Basu \& R. Kanbur (Eds) Arguments for a Better World, Vol. 1 (Oxford: Oxford University Press), pp. 50-67.

Robeyns, I. (2005) The capability approach: a theoretical survey, Journal of Human Development, 6(1), pp. 93-114.

Robeyns, I. (2006) The capability approach in practice, Journal of Political Philosophy, 17(3), pp. 351-376.

Robeyns, I. (2008) Sen's capability approach and feminist concerns, in: S. Alkire, F. Comim \& M. Qizilbash (Eds) The Capability Approach: Concepts, Measures, Applications (Cambridge: Cambridge University Press), pp. 82-104.

Robeyns, I. (2010) How can the capability approach be used to serve marginalized communities at the grassroots level? in: F. Apffel-Marglin, S. Kumar \& A. Mishra (Eds) Interrogating Development. Insights from the Margins (New Delhi: Oxford University Press), pp. 243-261. 
Schech, S. \& Haggis, J. (2000) Culture and Development: A Critical Introduction (Malden, MA: Blackwell Publishing).

Searle, J. (1995) The Construction of Social Reality (New York: Free Press).

Seekings, J. \& Nattrass, N. (2005) Class, Race and Inequality in South Africa (New Haven, CT: Yale University).

Sen, A. (1985) Well-being, agency and freedom. The Dewey lectures 1984, The Journal of Philosophy, 82(4), pp. 169-221.

Sen, A. (1992) Inequality Re-examined (Cambridge, MA: Harvard University Press).

Sen, A. (1999) Development as Freedom (New York: Knopf).

Sen, A. (2002) Response to commentaries, Studies in Comparative International Development, 37(2), pp. 78-86.

Simkins, C. (1983) Four Essays on the Past, Present and Possible Future of the Distribution of the Black Population of South Africa (Saldru: University of Cape Town).

Smith, M. L. \& Seward, C. (2009) The relational ontology of Amartya Sen, Journal of Human Development and Capabilities, 10(2), pp. 213-235.

Sogayise, Z. (2009) Personal interview.

Steinberg, J. (2008) Three Letter Plague: A Young Man's Journey Through a Great Epidemic (Johannesburg: Jonathan Ball).

Steinberg, J. (2011) The Politics of Disappointment, HUMA Seminar, UCT. 6 May 2011.

Stewart, F. (2005) Groups and capabilities, Journal of Human Development, 6(2), pp. 185204.

Taylor, C. (1992) Multiculturalism and the Politics of Recognition: An Essay (Princeton, NJ: Princeton University Press).

Terreblanche, S. (2002) A history of inequality in South Africa 1652-2002, Durban: UKZN Press and Sandton: KMM Review Publishing Company Pty Ltd..

Thompson, L. \& Conradie, I. (2011) From Poverty to power? Women's Participation in Intermediary Organisations in Site C, Khayelitsha, Africanus, 41(1), pp. 43-56.

Van der Berg, S. (2008) Poverty and Education, UNESCO. Available at: http://www.iiep.unesco.org/fileadmin/user_upload/Info_Services_Publications/pdf /2009/EdPol10.pdf (downloaded 25 November 2011).

West, M. (1982) From pass courts to deportation: changing patterns of influx control in Cape Town, African Affairs, 81(325), pp. 463-477.

Wolpe, H. (1988) Race, Class and the Apartheid State (London: James Curry). 